\title{
INTERICTAL EPILEPTIFORM ACTIVITY IN SLEEP AND WAKEFULNESS IN PATIENTS WITH TEMPORAL LOBE EPILEPSY
}

Broutian AG $\otimes$, Belyakova-Bodina Al, Dolgova SM, Pushkar TN, Abramova AA

Research Center of Neurology, Moscow, Russia

Sleep is an important activator of epileptiform activity, with epileptiform discharge (ED) probability varying among sleep stages. The aim of our study was to analyze the association between epileptiform activity and sleep stages or wakefulness in adults with temporal discharges. We analyzed 32 long-term overnight EEG recordings. All focal discharges were marked, and the entire sleep was staged. Absolute general epileptiform discharge index (EDI), defined as a ratio of total ED number to the full recording time in hours, as well as absolute EDIs for REM, N1, N2 and N3 stages were calculated. The majority of patients (28) had the highest EDI in N3. EDI increased significantly while sleep progressed to deeper stages, reaching its peak in N3. In REM sleep, EDI sharply declined $(p<0.01)$ reaching the levels of wakefulness. Increasing synchronization of cortical neurons is thought to be the major mechanism of EDI rise in NREM sleep. Hence, N3 seems to be the most sensitive stage to capture EDs, which highlights the importance of deep sleep recording in patients with temporal epilepsy.

Keywords: electroencephalography, sleep, epileptiform activity, epilepsy, temporal lobe epilepsy

Author contribution: Broutian AG — research planning, literature analysis, data interpretation, manuscript drafting; Belyakova-Bodina Al, Abramova AA — data collection, analysis, interpretation, manuscript drafting; Dolgova SM, Pushkar TN — data collection, analysis.

Compliance with ethical standards: the study was approved by the Research Center of Neurology Ethics Committee (protocol № 1-4/19 of January 23, 2019).

$\triangle$ Correspondence should be addressed: Amayak G. Broutian

Leningradsky Prospect, 33, Moscow, 125284; abroutian@mail.ru

Received: 23.08.2019 Accepted: 30.09.2019 Published online: 02.11.2019

DOI: 10.24075/brsmu.2019.073

\section{ИНТЕРИКТАЛЬНАЯ ЭПИЛЕПТИФОРМНАЯ АКТИВНОСТЬ ВО СНЕ И В БОДРСТВОВАНИИ У ПАЦИЕНТОВ С ВИСОЧНОЙ ЭПИЛЕПСИЕЙ}

\author{
А. Г. Брутян 凶, А. И. Белякова-Бодина, С. М. Долгова, Т. Н. Пушкарь, А. А. Абрамова
}

Научный центр неврологии, Москва, Россия

Сон является значимым активатором эпилептиформной активности, при этом вероятность регистрации разрядов может меняться в зависимости от стадии и глубины сна. Целью исследования было оценить зависимость эпилептиформной активности от уровня бодрствования и глубины сна в популяции взрослых пациентов с височной локализацией разрядов. Нами было проанализировано 32 продолженных ЭЭГ-мониторинга с записью ночного сна, в которых были отмечены все фокальные разряды, а также проводилось стадирование сна. Определяли общий индекс эпилептиформной активности, как отношение общего количества разрядов к длительности исследования в часах, а также индивидуальные индексы эпилептиформной активности для бодрствования и каждой из стадий сна: для REM-фазы и N1, N2 и N3 стадий NREM-сна. У подавляющего числа пациентов (28) максимальный индекс зарегистрирован в стадии N3. По мере перехода к более глубоким стадиям сна, индекс разрядов последовательно и достоверно увеличивался, достигая максимальных величин в стадии N3 $(p<0,01)$. В фазу REM-сна индекс резко снижался $(p<0,01)$, приближаясь к значениям, зарегистрированным в бодрствовании. Основным механизмом, который приводит к увеличению индекса эпилептиформной активности в NREM-сне, может быть нарастающая синхронизация корковых нейронов с увеличением доли медленной активности в ЭЭГ. Таким образом, стадия 그 является наиболее информативной в плане регистрации фокальных разрядов, что диктует необходимость достижения достаточной глубины сна при проведении диагностических ЭЭГ исследований у пациентов с височными формами эпилепсии.

Ключевые слова: электроэнцефалография, сон, эпилептиформная активность, эпилепсия, височная эпилепсия

Информация о вкладе авторов: А. Г. Брутян - планирование исследования, анализ литературы, интерпретация данных, подготовка черновика рукописи; А. И. Белякова-Бодина, А. А. Абрамова - сбор, анализ, интерпретация данных, подготовка черновика рукописи; С. М. Долгова, Т. Н. Пушкарь сбор, анализ данных.

Соблюдение этических стандартов: исследование одобрено этическим комитетом ФГБНУ НЦН (протокол № 1-4/19 от 23 января 2019 г.)

Для корреспонденции: Амаяк Грачевич Брутян

Ленинградский проспект, д. 33, г. Москва, 125284; abroutian@mail.ru

Статья получена: 23.08.2019 Статья принята к печати: 30.09.2019 Опубликована онлайн: 02.11.2019

DOI: $10.24075 /$ vrgmu.2019.073

The likelihood of developing epileptic seizures depending on the level of wakefulness and sleep depth is largely determined by the epilepsy and seizure type [1, 2]. For example, in juvenile myoclonic epilepsy seizures typically occur after awakening while in autosomal dominant nocturnal frontal lobe epilepsy they only happen during sleep. Sleep is also known to be a significant activator of interictal epileptiform activity in electroencephalography (EEG), which is more common for focal discharges than for generalized ones [3].

Sleep, however, is not a homogeneous state; it consists of several states changing in a cyclic manner. These states differ in depth, physiological parameters, and EEG patterns.
A remarkable example is epileptic encephalopathy with continuous spikes and waves during sleep (CSWS) in which epileptic discharges almost replace the physiological patterns of non-rapid eye movements sleep (NREM sleep) and disappear during rapid eye movements (REM) sleep.

Thus, the probability of epileptiform activity is expected to depend on sleep stage. Furthermore, ED number during a certain sleep stage should be related to the duration of this sleep stage. For example, stage 2 prevails in a healthy person's sleep, which may mislead an EEG interpreter into thinking that EDs are the most prevalent during this stage. 
Epileptiform discharge index (EDI) is described for both generalized and focal forms of epilepsy [4-8]. Studies on focal discharges differ in number of patients, discharge localization and epileptiform activity index calculation methods. In the majority of studies, discharges were calculated in 5 to 20-minute intervals of wakefulness and each stage of sleep. Both discharge localization and calculation methods can affect the results [4-8].

Temporal epilepsy is the most common, comprising two thirds of all focal epilepsies [9]. The aim of this study was to assess the effect of various stages of sleep on interictal epileptiform activity in a relatively homogeneous group of adults with temporal lobe epilepsy by counting and analyzing EDs throughout the entire EEG recordings.

\section{METHODS}

We scanned video EEG recordings obtained in the Research Center of Neurology from February 2018 through June 2019 to select overnight recordings only. We found 709 recordings which were 10 to 12 hours long and included night sleep, evening and morning wakefulness. Initially, 142 recordings with focal epileptiform activity regardless of the disease duration and antiepileptic drug regimen were chosen. Inclusion criteria were the following: 1) only temporal ED localisation; 2) in case of repeated recordings, the first one was analyzed; 3) all sleep stages were present; 4) manual ED detection only, no automatic algorithms were used; 5) at least 10 EDs in a recording. Exclusion criteria were: 1) epileptic seizures during recording; 2) more than 500 EDs. Recordings with epileptic seizures were excluded due to their potential effect on EDI. Recordings with more than 500 EDs were excluded because of the technical limitations of ED manual detection. Finally, 32 recordings that met all the criteria were included in our study. Among the included patients there were 17 females and 15 males, aged 19 to 79 years (median 41 years).

EEG was recorded with scalp electrodes placed according to 10-20 international system with additional EKG channel. In 11 recordings, an inferior temporal chain (F9, F10, T9, T10, P9, P10) was used as well. EEG was recorded with NicOne (Natus,
USA) and BePlus LTM (EBNeuro; Italy) systems. Recordings started between 20:00 and 21:00 and ended between 07:00 and 08:00. Photic stimulation and 5-minute hyperventilation were performed in the beginning of the recordings and after awakening in the morning. Epileptiform activity was defined according to 2017 revised glossary of EEG terms [10]. Total number of EDs varied from 13 to 401 (median 72 EDs). 27 patients (84\%) showed unilateral EDs, 5 patients showed bilateral EDs. Number of patients with left-sided or predominantly left-sided EDs (17) was comparable to the number of patients (15) with right-sided or predominantly right-sided EDs.

Sleep was staged using 30-second epochs in accordance with American Academy of Sleep Medicine Manual for the Scoring of Sleep and Associated Events [11]. Since we did not use electrooculographic (EOG) electrodes and electromyographic (EMG) chin electrodes, REM sleep was identified based on indirect signs, such as ocular artefacts in frontal channels, muscle artifacts and REM-sleep-specific EEG patterns [11]. In this paper, we used traditional designations for sleep stages and wakefulness: Wake for wakefulness, N1 for stage 1, N2 for stage 2, N3 for stage 3 (slow-wave sleep), REM for REM sleep. Figure 1 shows an example of a hypnogram with ED marks.

We created hypnograms and marked EDs on them for each recording and calculated the following indices: 1) absolute general EDI, defined as a ratio of total ED count to the full recording time in hours; 2) absolute EDI for wakefulness and each sleep stage (N1, N2, N3, REM), defined as a ratio of ED count during stage to its duration in hours. For bilateral EDs, average EDI from both sides were calculated. The range of absolute EDIs was substantial. Since our study mainly focused on the trends of EDIs in relation to sleep stages and wakefulness, we did additional normalization, calculating relative EDls, defined as a ratio of absolute stage EDI to absolute general EDI. Further in the text, EDI should be regarded as relative EDI, unless otherwise specified.

STATISTICA 12.6 software (Statsoft, Dell Software; USA) was used for statistical processing of the results. We applied the Shapiro-Wilk normality test for distribution characteristics, Mann-Whitney test for independent samples and Wilcoxon test

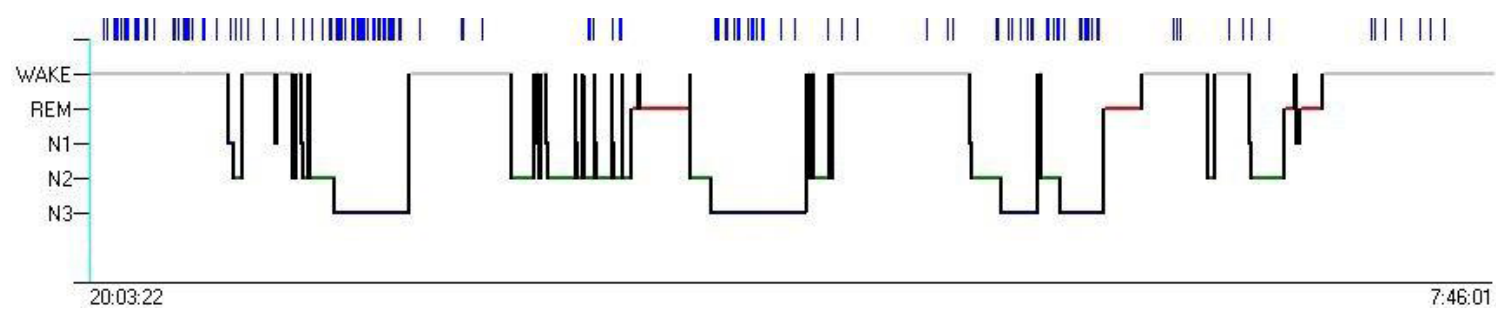

Fig. 1. An example of a hypnogram with ED marks. X-axis shows astronomical time. Y-axis shows sleep stages and wakefulness. Blue vertical lines in the top are ED marks. Wake, wakefulness periods; N1, stage 1; N2, stage 2; N3, stage 3 (slow-wave sleep); REM, REM sleep

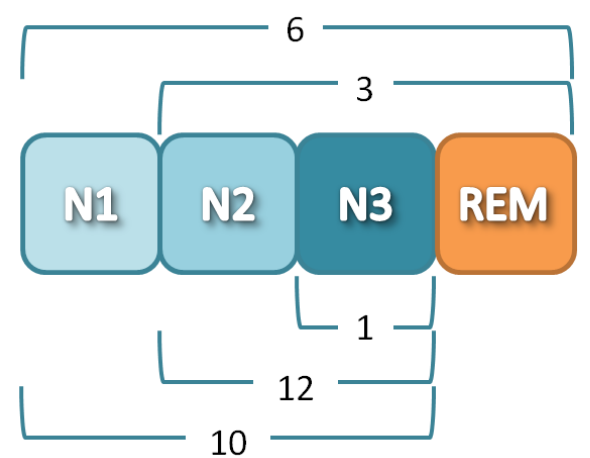

Fig. 2. Registered combinations of sleep stages with EDs. Combinations of sleep stages with EDs are highlighted with braces. Numbers in the middle of the braces reflect the number of patients with certain ED distribution 
Table 1. The number of recordings having EDs in certain sleep stages or wakefulness and average relative EDls

\begin{tabular}{|l|c|c|c|c|}
\hline \multicolumn{1}{|c|}{ Stage } & Wake & N1 & N2 & REM \\
\hline Number of patients with/without discharges at this stage & $18 / 14$ & $16 / 16$ & $31 / 1$ & $32 / 0$ \\
\hline Number of patients with maximum discharges at this stage & 2 & 0 & 1 & 28 \\
\hline Relative discharge index, median [lower; upper quartile] & $0.03[0 ; 0.23]$ & $0.11[0 ; 0.89]$ & $1.19[0.64 ; 1.64]$ & $3.92[2.74 ; 6.64]$ \\
\hline
\end{tabular}

for dependent samples. Spearman's rank correlation coefficient was used to calculate the correlation. The differences were considered statistically significant at $p<0.05$.

\section{RESULTS}

18 patients (56\%) had EDs while being awake, 16 patients $(50 \%)$ had EDs in N1, 31 patients $(97 \%)$ had EDs in N2, all the patients had EDs in N3 and 9 patients (28\%) had EDs in REM sleep (Table 1). The combinations of wakefulness and sleep stages with EDs varied (Fig. 2). No recording showed EDs exclusively in wakefulness, N1, N2 or REM. Nevertheless, one recording revealed EDs only in N3.

Stages with the largest EDI were identified. 28 patients $(87.5 \%)$ had the largest EDI in N3, 2 patients had the largest EDI in wakefulness period, 1 patient had the largest EDI in N2, 1 patient had the largest EDI in REM, no patients were shown to have the largest EDI in N1.

Relative EDls with trends are shown in Fig. 3. The median EDls were: 0.03 for wakefulness periods, 0.11 for N1, 0.19 for N2, 3.92 for N3, 0.19 for REM (Table 1, Fig. 4). Application of the Wilcoxon signed-rank test revealed a significantly higher EDI in NREM sleep compared to that of wakefulness: $p<0.05$ for N1 and $p<0.01$ for N2 and N3, with difference from REM being not significant. N3 EDI was significantly larger than EDI for other stages. EDI for REM was significantly smaller than EDI for each NREM sleep stage. EDI for REM had no significant difference from EDI for wakefulness period.

We divided our sample into 2 groups according to the total ED number: patients with small ED number (14 to 75 EDs) and large ED number (75 to 401 EDs). We compared EDls between these groups and found no significant difference.

We performed correlation analysis for absolute stage/ EDls and found significant correlation between EDI for N1 and REM, $\mathrm{N} 1$ and $\mathrm{N} 2$, and $\mathrm{N} 2$ and N3.

There was no significant EDI difference between left and right side temporal discharges in either wakefulness or sleep.

\section{DISCUSSION}

Our study showed N3 EDIs to be substantially higher than EDIs in other stages. ED predominance in slow-wave sleep was shown in earlier studies, in which EDI was analyzed for each sleep stage $[6-8,12-14]$. There were no patients without EDs in N3 in our study, and EDs in N3 were on average three times more probable than in N2. Comparing stages that harbored the majority of EDs within a single EEG recording revealed even greater difference, as recordings with the majority of EDs in N3

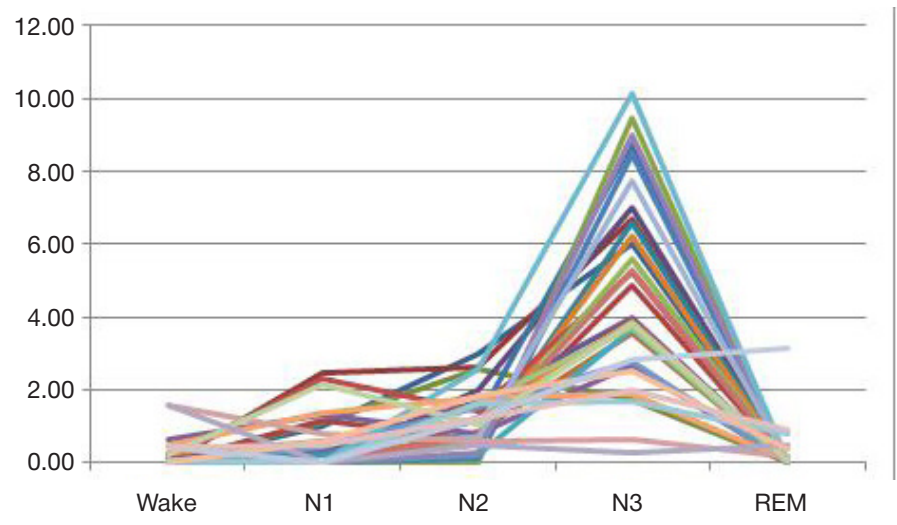

Fig. 3. Trends of EDls for each sleep stage and wakefulness in patients with temporal discharges

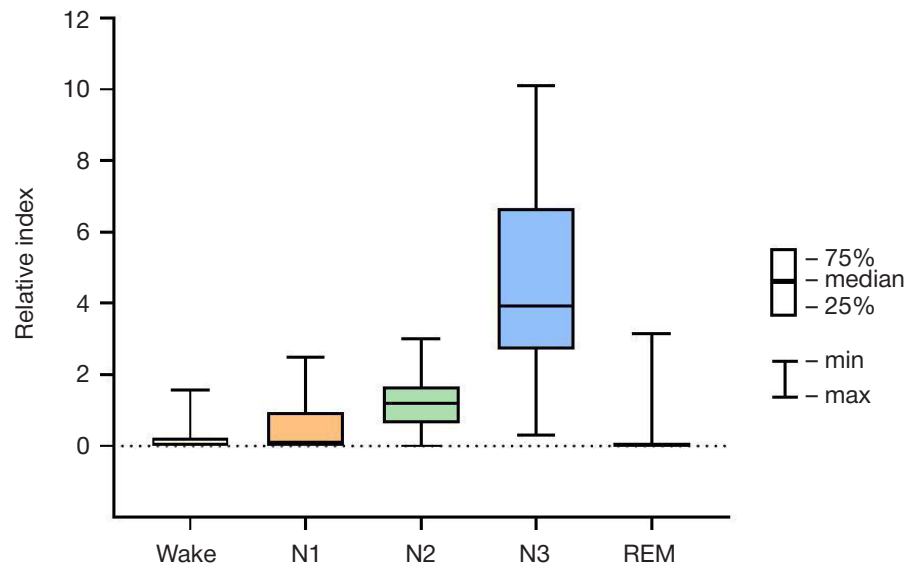

Fig. 4. Relative EDIs for each sleep stage and wakefulness in patients with temporal discharges 
had a share of $87.5 \%$. Analyzing the numerical data (Table 1) and EDI trending (Fig. 3), we observed a burst in N3. Similar to N3, EDI in N2, being smaller than in N3, was still significantly larger than in wakefulness, N1 and REM. We found no previous studies that showed significant difference in EDIs for N1 and N2. The lack of such statistical significance in earlier studies may be attributed to the method of ED marking, which was performed in selected intervals of EEG recordings rather than throughout the whole recordings $[8,15,16]$.

Hence, we observed EDI increasing with sleep progression from REM to N1, N2 and N3.

Such EDI changes through the sleep stages may be explained by increased synchronization of neural networks in NREM sleep. Scalp EEG electrodes are known to require quite a large number of cortical neurons to discharge synchronously. Experimental data suggest that such synchronously discharging neurons should occupy at least an area of $6-8 \mathrm{~cm}^{2}$. Slow activity, mainly that of delta range, is known to reflect high synchronization of cortical neurons. A characteristic feature of N3 is high-amplitude delta activity occupying at least $20 \%$ of an epoch. However, thorough analysis may reveal gradual increase of slow-wave activity occurring already in N2. Apart from slow-wave activity not sufficient to meet N3 criteria, N2 is characterized by the presence of $\mathrm{K}$-complexes which is the most important criterion of this sleep stage. K-complexes are relatively slow high-amplitude transients which may embed EDs, becoming the so-called epileptic K-complexes. Such epileptic $\mathrm{K}$-complexes can be found in both generalized and focal epilepsy [17, 18]. Furthermore, nocturnal frontal lobe epilepsy seizures have been shown to be associated with K-complexes [19]. Hence, an increased probability of EDs in NREM sleep may be considered as a consequence of increased synchronization of neural networks. This is supported by studies which showed positive correlation between ED frequency and delta band power.

Despite sleep in general being the most potent ED activator, REM sleep harbored the least of sleep EDs, with the index of epileptiform activity being comparable to such of wakefulness. Our data are consistent with earlier studies of the effect of REM sleep on epileptiform activity $[8,14,21,22]$. In all the studies, EDI in REM was the lowest among sleep stages. Compared to wakefulness, EDI in REM sleep was shown to be slightly lower in the majority of studies. Having no activating effect on epileptiform activity, REM sleep, however, has two aspects that draw our attention. Firstly, if occurring in REM sleep, EDs tend to be more localized, thus having greater localizing value than in other sleep stages [23, 24]. Secondly, REM sleep, being an integral part of healthy sleep, not only has no activating effect on epileptiform activity, but also reduces its probability. Thus, to some extent, activity of neural networks in REM sleep is protective, reducing the probability of not only EDs, but also seizures [3].

Our study results might have been affected by several factors. Firstly, we intentionally excluded patients with exceedingly large numbers of EDs, which were hard to be counted manually. In some earlier studies, ED counting was selective, i.e. EDs were marked in limited stretches of time (5-20 minutes to 1 hour) with further extrapolation to the entire EEG recording [8, 14, 15 , 25]. We also occasionally use selective ED count in practice; however, we did not include recordings analyzed in such a way in order to avoid probable bias. Secondly, REM sleep duration might have been underestimated because of the lack of EMG channels reflecting the activity of mentalis muscle. Thirdly, wakefulness EDls might have been overestimated, as 5-minute hyperventilation tests included in wakefulness periods increase the neuronal synchronization by reducing cerebral blood flow and thus may activate ED. Nevertheless, NREM sleep is a much stronger activator compared to hyperventilation [15]. Fourthly, the effect of antiepileptic therapy, time from the first seizure, seizure frequency and semiology, drug resistance and structural lesions on MRI was not analyzed.

From a practical point of view, our study highlights the importance of slow-wave sleep recording in EEG diagnostic investigations, especially if focal epilepsy is suspected. Short-term EEG, particularly 20-minute routine EEG, provide lower probability to record EDs, thus diminishing sensitivity of these tests in the diagnosis of epilepsy, especially its focal forms. As a result, a precise diagnosis and correct treatment initiation might be delayed.

\section{CONCLUSIONS}

Our study on a sample of patients with temporal epileptiform activity showed that relative EDI for focal discharges increases while NREM progresses from N1 to N3. In REM sleep, EDI drops significantly to the level comparable to wakefulness. The most likely mechanism behind the significant predominance of EDs in the slow-wave sleep is synchronization of cortical neurons. Lack of records describing the N3 stage, which is when the epileptiform activity reaches its maximum, or the insufficient duration of this stage significantly reduce the likelihood of epileptiform activity recording, and when the clinical manifestation is insufficiently convincing, this lack of information can lead to erroneous conclusions, and to a delay in making the correct diagnosis and proper treatment initiation.

\section{References}

1. Minecan D, Natarajan A, Marzec M, Malow B. Relationship of epileptic seizures to sleep stage and sleep depth. Sleep. 2002; 25 (8): 899-904.

2. Bazil CW. Seizure modulation by sleep and sleep state. Brain Res. 2019; (1703): 13-17.

3. $\mathrm{Ng} \mathrm{M}$, Pavlova M. Why are seizures rare in rapid eye movement sleep? Review of the frequency of seizures in different sleep stages. Epilepsy Res Treat. 2013; (2013): 932790.

4. Kellaway P, Frost JD, Crawley JW. Time modulation of spikeand-wave activity in generalized epilepsy. Ann Neurol. 1980; 8 (5): 491-500.

5. Halász P, Terzano MG, Parrino L. Spike-wave discharge and the microstructure of sleep-wake continuum in idiopathic generalised epilepsy. Neurophysiol Clin. 2002; 32 (1): 38-53.
6. Lieb JP, Joseph JP, Engel J, Walker J, Crandall PH. Sleep state and seizure foci related to depth spike activity in patients with temporal lobe epilepsy. Electroencephalogr Clin Neurophysiol. 1980; 49 (5-6): 538-57.

7. Sammaritano M, Gigli GL, Gotman J. Interictal spiking during wakefulness and sleep and the localization of foci in temporal lobe epilepsy. Neurology. 1991; 41 (2 (Pt 1): 290-7.

8. Clemens Z, Janszky J, Clemens B, Szucs A, Halász P. Factors affecting spiking related to sleep and wake states in temporal lobe epilepsy (TLE). Seizure. 2005; 14 (1): 52-7.

9. Semah F, Picot MC, Adam C, Broglin D, Arzimanoglou A, Bazin B, et al. Is the underlying cause of epilepsy a major prognostic factor for recurrence? Neurology. 1998; 51 (5): 1256-62.

10. Kane N, Acharya J, Benickzy S, Caboclo L, Finnigan S, Kaplan PW, 
et al. A revised glossary of terms most commonly used by clinical electroencephalographers and updated proposal for the report format of the EEG findings. Revision 2017. Clin Neurophysiol Pract. 2017; (2): 170-85

11. Berry RB, Brooks R, Gamaldo CE, Harding SM, Lloyd RM, Marcus CL, et al. The AASM Manual for the Scoring of Sleep and Associated Events: Rules, Terminology and Technical Specifications, Version 2.2. www.aasmnet.org. Darien, Illinois: American Academy of Sleep Medicine, 2015.

12. Malow BA, Kushwaha R, Lin X, Morton KJ, Aldrich MS. Relationship of interictal epileptiform discharges to sleep depth in partial epilepsy. Electroencephalogr Clin Neurophysiol. 1997; 102 (1): 20-6.

13. Clemens Z, Janszky J, Szucs A, Békésy M, Clemens B, Halász P. Interictal epileptic spiking during sleep and wakefulness in mesial temporal lobe epilepsy: a comparative study of scalp and foramen ovale electrodes. Epilepsia. 2003; 44 (2): 186-92.

14. Singh S, Shukla G, Goyal V, Srivastava AK, Singh MB, Vibha D, et al. Impact of sleep on the localizing value of video EEG in patients with refractory focal seizures - a prospective video-EEG with EOG and submental EMG study. Clin Neurophysiol. 2014; 125 (12): 2337-43.

15. Klein KM, Knake S, Hamer HM, Ziegler A, Oertel WH, Rosenow F. Sleep but not hyperventilation increases the sensitivity of the EEG in patients with temporal lobe epilepsy. Epilepsy Res. 2003; 56 (1): 43-9.

16. Yu YL, Yan YL, Tian SF, Feng ZH, Shi MT. Circadian rhythm of interictal epileptiform discharges and changes of spindles in patients with temporal lobe epilepsy. Biomed Res. 2018; 29 (6): 1263-7.

17. Geyer JD, Carney PR, Gilliam F. Focal epileptiform spikes in

\section{Литература}

1. Minecan D, Natarajan A, Marzec M, Malow B. Relationship of epileptic seizures to sleep stage and sleep depth. Sleep. 2002; 25 (8): 899-904.

2. Bazil CW. Seizure modulation by sleep and sleep state. Brain Res. 2019; (1703): 13-17.

3. $\mathrm{Ng} \mathrm{M}$, Pavlova M. Why are seizures rare in rapid eye movement sleep? Review of the frequency of seizures in different sleep stages. Epilepsy Res Treat. 2013; (2013): 932790

4. Kellaway P, Frost JD, Crawley JW. Time modulation of spike-andwave activity in generalized epilepsy. Ann Neurol. 1980; 8 (5): 491-500.

5. Halász P, Terzano MG, Parrino L. Spike-wave discharge and the microstructure of sleep-wake continuum in idiopathic generalised epilepsy. Neurophysiol Clin. 2002; 32 (1): 38-53.

6. Lieb JP, Joseph JP, Engel J, Walker J, Crandall PH. Sleep state and seizure foci related to depth spike activity in patients with temporal lobe epilepsy. Electroencephalogr Clin Neurophysiol. 1980; 49 (5-6): 538-57.

7. Sammaritano M, Gigli GL, Gotman J. Interictal spiking during wakefulness and sleep and the localization of foci in temporal lobe epilepsy. Neurology. 1991; 41 (2 (Pt 1): 290-7.

8. Clemens Z, Janszky J, Clemens B, Szucs A, Halász P. Factors affecting spiking related to sleep and wake states in temporal lobe epilepsy (TLE). Seizure. 2005; 14 (1): 52-7.

9. Semah F, Picot MC, Adam C, Broglin D, Arzimanoglou A, Bazin B, et al. Is the underlying cause of epilepsy a major prognostic factor for recurrence? Neurology. 1998; 51 (5): 1256-62.

10. Kane N, Acharya J, Benickzy S, Caboclo L, Finnigan S, Kaplan PW, et al. A revised glossary of terms most commonly used by clinical electroencephalographers and updated proposal for the report format of the EEG findings. Revision 2017. Clin Neurophysiol Pract. 2017; (2): 170-85.

11. Berry RB, Brooks R, Gamaldo CE, Harding SM, Lloyd RM, Marcus CL, et al. The AASM Manual for the Scoring of Sleep and Associated Events: Rules, Terminology and Technical Specifications, Version 2.2. www.aasmnet.org. Darien, Illinois: American Academy of Sleep Medicine, 2015.

12. Malow BA, Kushwaha R, Lin X, Morton KJ, Aldrich MS. Relationship of interictal epileptiform discharges to sleep depth in partial conjuction with K-complexes. J Clin Neurophysiol. 2006; 23 (5): 437-40.

18. Niedermeyer E. Epileptiform $\mathrm{K}$ complexes. Am J Electroneurodiagnostic Technol. 2008; 48 (1): 48-51.

19. ElHelou J, Navarro V, Depienne C, Fedirko E, LeGuern E, Baulac M, et al. K-complex-induced seizures in autosomal dominant nocturna frontal lobe epilepsy. Clin Neurophysiol. 2008; 119 (10): 2201-4.

20. Ferrillo F, Beelke M, DeCarli F, Cossu M, Munari C, Rosadini G, et al. Sleep-EEG modulation of interictal epileptiform discharges in adult partial epilepsy: a spectral analysis study. Clin Neurophysiol. 2000; 111 (5): 916-23

21. Malow BA, Lin X, Kushwaha R, Aldrich MS. Interictal spiking increases with sleep depth in temporal lobe epilepsy. Epilepsia. 1998; 39 (12): 1309-16.

22. Campana C, Zubler F, Gibbs S, deCarli F, Proserpio P, Rubino A1, et al. Suppression of interictal spikes during phasic rapid eye movement sleep: a quantitative stereo-electroencephalography study. J Sleep Res. 2017; 26 (5): 606-13.

23. Malow BA, Aldrich MS. Localizing value of rapid eye movement sleep in temporal lobe epilepsy. Sleep Med. 2000; 1 (1): 57-60.

24. Ochi A, Hung R, Weiss S, Widjaja E, To T, Nawa Y, et al. Lateralized interictal epileptiform discharges during rapid eye movement sleep correlate with epileptogenic hemisphere in children with intractable epilepsy secondary to tuberous sclerosis complex. Epilepsia. 2011; 52 (11): 1986-94.

25. Scarlatelli-Lima AV, Sukys-Claudino L, Watanabe N, Guarnieri R, Walz R, Lin K. How do people with drug-resistant mesial temporal lobe epilepsy sleep? A clinical and video-EEG with EOG and submental EMG for sleep staging study. eNeurologicalSci. 2016; (4): 34-41.

epilepsy. Electroencephalogr Clin Neurophysiol. 1997; 102 (1): 20-6. 13. Clemens Z, Janszky J, Szucs A, Békésy M, Clemens B, Halász P. Interictal epileptic spiking during sleep and wakefulness in mesial temporal lobe epilepsy: a comparative study of scalp and foramen ovale electrodes. Epilepsia. 2003; 44 (2): 186-92.

14. Singh S, Shukla G, Goyal V, Srivastava AK, Singh MB, Vibha D, et al. Impact of sleep on the localizing value of video EEG in patients with refractory focal seizures - a prospective video-EEG with EOG and submental EMG study. Clin Neurophysiol. 2014; 125 (12): 2337-43.

15. Klein KM, Knake S, Hamer HM, Ziegler A, Oertel WH, Rosenow F. Sleep but not hyperventilation increases the sensitivity of the EEG in patients with temporal lobe epilepsy. Epilepsy Res. 2003; 56 (1): 43-9.

16. Yu YL, Yan YL, Tian SF, Feng ZH, Shi MT. Circadian rhythm of interictal epileptiform discharges and changes of spindles in patients with temporal lobe epilepsy. Biomed Res. 2018; 29 (6): 1263-7.

17. Geyer JD, Carney PR, Gilliam F. Focal epileptiform spikes in conjuction with K-complexes. J Clin Neurophysiol. 2006; 23 (5): 437-40.

18. Niedermeyer E. Epileptiform $K$ complexes. Am J Electroneurodiagnostic Technol. 2008; 48 (1): 48-51.

19. ElHelou J, Navarro V, Depienne C, Fedirko E, LeGuern E, Baulac M, et al. K-complex-induced seizures in autosomal dominant nocturnal frontal lobe epilepsy. Clin Neurophysiol. 2008; 119 (10): 2201-4.

20. Ferrillo F, Beelke M, DeCarli F, Cossu M, Munari C, Rosadini G, et al. Sleep-EEG modulation of interictal epileptiform discharges in adult partial epilepsy: a spectral analysis study. Clin Neurophysiol. 2000; 111 (5): 916-23.

21. Malow BA, Lin X, Kushwaha R, Aldrich MS. Interictal spiking increases with sleep depth in temporal lobe epilepsy. Epilepsia. 1998; 39 (12): 1309-16.

22. Campana C, Zubler F, Gibbs S, deCarli F, Proserpio P, Rubino A1, et al. Suppression of interictal spikes during phasic rapid eye movement sleep: a quantitative stereo-electroencephalography study. J Sleep Res. 2017; 26 (5): 606-13.

23. Malow BA, Aldrich MS. Localizing value of rapid eye movement sleep in temporal lobe epilepsy. Sleep Med. 2000; 1 (1): 57-60 
24. Ochi A, Hung R, Weiss S, Widjaja E, To T, Nawa Y, et al. Lateralized interictal epileptiform discharges during rapid eye movement sleep correlate with epileptogenic hemisphere in children with intractable epilepsy secondary to tuberous sclerosis complex. Epilepsia. 2011; 52 (11): 1986-94.
25. Scarlatelli-Lima AV, Sukys-Claudino L, Watanabe N, Guarnieri R, Walz R, Lin K. How do people with drug-resistant mesial temporal lobe epilepsy sleep? A clinical and video-EEG with EOG and submental EMG for sleep staging study. eNeurologicalSci. 2016; (4): 34-41. 